\title{
Makna Kelong Salonreng pada Upacara Adat Perkawinan Masyarakat Desa Ara Kabupaten Bulukumba (Suatu Tinjauan Semiotika Marcel Danesi)
}

\author{
Runimeirati \\ Program Studi Ilmu Komputer/Fakultas Ilmu \\ Komputer/Universitas \\ Megarezky/BTN. Andi Tonro Permai Blok B9 No.17, \\ Sungguminasa Kab. Gowa, Sulawesi Selatan \\ runimeirati@gmail.com
}

\begin{abstract}
Abstrak
Penelitian ini bertujuan menganalisis makna Kelong Salonreng dalam sebuah ritual adat di masyarakat Bulukumba, mengkaji totalitas makna Kelong Salonreng berdasarkan teori semotika Marcel Danesi. Penelitian ini adalah penelitian kepustakaan dan merupakan penelitian deskriptif kualitatif. Sumber data dalam penelitian ini adalah keseluruhan makna Kelong Salonreng. Data primer diperoleh dari beberapa informan yang paham dan tahu soal objek penelitian. Teknik pengumpulan data pada penelitian ini adalah secara observasi, wawancara, dokumentasi, dan pencatatan. Sedangkan, teknik analisis datanya yaitu dengan mengidentifikasi semua pesan dan tanda teks Kelong Salonreng, transliterasi dan pengklasifikasian makna. Dapat disimpulkan yakni (1) Setiap bait dalam teks Salonreng merupakan bentuk kesyukuran masyarakat Ara kepada Sang Pencipta, (2) Pola persajakan Kelong Salonreng serupa dengan pola persajakan Makassar 8-8-48, (3) Tari Saloreng merupakan perkembangan dari tari rakyat dengan gerakan yang sangat sederhana yang dimainkan secara tunggal ataupun berkelompok penari wanita, (4) Sebagai penghormatan kepada leluhur atau digunakan untuk menghalau roh-roh jahat serta memohon perlindungan dari Dewata.
\end{abstract}

Kata kunci : Kelong Salonreng, Semiotik dan Kabupaten Bulukumba.

\section{Pendahuluan}

Eksistensi manusia di dunia ditandai dengan upaya tiada hentihentinya untuk menjadi manusia seutuhnya. Upaya ini berlangsung dalam dunia ciptaannya sendiri, yang berbeda dengan dunia alamiah, yakni kebudayaan. Kebudayaan merupakan penanda identitas budaya. Kebudayaan mencakup pembahasan yang luas dan multidiskursus. Matra kebudayaan dapat dilihat dalam berbagai aspek yang di antaranya meliputi etika, estetika, intelektualitas, dan artefak-artefak penanda materil. Karya sastra yang dihasilkan oleh masyarakat Bulukumba khusunya Ara, berupa kelong yang ditampilkan pada upacara adat perkawinan menandakan bahwa setiap karya yang diciptakan masyarakat tersebut tidak pernah lepas dari hal-hal yang berhubungan dengan kegiatan sehari-hari. Pola upacara adat ini 
mempunyai bentuk dan cirri tersendiri di mana dalam upacara ini ditampilkan permainan yang disebut "akkarenasiusiri". Kelong Salonreng merupakan warisan nenek moyang secara turun temurun bersama kesenian lainnya. Yang menjadi focus masalah dalam penelitian ini adalah makna Kelong Salonreng pada upacara adat perkawinan masyarakat Ara Kabupaten Bulukumba ditinjau dari teori semiotika Marcel Danesi, dan bentuk interelasi makna yang terkandung dalam Kelong Salonreng dihubungkan dengan kehidupan social masyarakat Desa Ara Kabupaten Bulukumba. Semiotika Marcel Danesi menekankan pada kajian Pesan, Tanda dan Makna yang terkandung dalam suatu teks, ketiga hal inilah yang diharapkan akan membedah teks Lontarak Salonreng. Kegiatan penelitian tentang makna Kelong Salonreng pada upacara adat perkawinan masyarakat Ara bertujuan (1) Mendeskripsikan pesan yang terkandung dalam Kelong Salonreng berdasarkan teori semiotika Marcel Danesi. (2) Mendeskripsikan tanda apa saja yang digunakan dalam Kelong Salonreng dihubungkan dengan kehidupan sosial budaya masyarakat Desa Ara Kabupaten Bulukumba, dan yang ketiga (3) Mendeskripsikan makna yang tersurat dalam teks Lontarak Salonreng. Penelitian ini diharapkan dapat bermanfaat secara teoretis maupun secara praktis.

\section{Metode Penelitian Jenis Penelitian}

Pada penelitina ini metode penelitian yang digunakan adalah penelitian kualitatif. Dimana proses penelitiannya menggunakan wawancara pada narasumber dan lebih banyak menelaah sumber literatur yang ada yang terkait dengan objek penelitian.

\section{Waktu dan Tempat Penelitian}

Penelitian ini akan dilaksanakan pada Bulan April 2020 hingga Juni 2020 di Desa Ara, Kecamatan Bontobahari Kabupaten Bulukumba, Sulawesi Selatan.

\section{Tahap Pelaksanaan}

\section{Tahap Persiapan}

Pada tahap ini peneliti mempersiapkan segala sesuatu, seperti surat perizinan, mengidentifikasi dan merumuskan masalah, mengumpulakn literatur dan membuat daftar pertanyaan untuk informan, Menyusun jadwal wawancara dan segala alat pendukung yang akan digunakan sebelum turun lapang.

2. Tahap Pelaksanaan

Melakukan wawancara informasn, melakukn observasi, melakukan Halaman | 601 
sintesa dan memilih data yang sesuai dengan kebutuhan yang didapatkan dilapangan.

\section{Tahap Penyusunan Laporan}

Menysun laporan hasi penelitian yang telah dilakukan.

\section{Jenis Data}

Penelitian ini menggunakan data lisan yang diperoleh melalui proses wawancara dan data tulisan yang berasal dari buku sejarah ataupun kumpulan teks Salonreng yang sudah dibukunann beberapa yang dimiliki oleh informan.

\section{Hasil Penelitian}

1. Makna Kelong Salonreng ditinjau dari Teori Semiotika Marcel Danesi Berdasarkan teori Marcel Danesi yang membahas mengenai pesan, tanda dan makna, maka Kelong Salonreng di bawah ini dipaparkan secara lengkap pesan dari Kelong Salonreng, penandanya dalam kehidupan sosial masyrakat dan maknanya secara keseluruhan.

Adapun deskripsi teks Kelong Salonreng, sebagai berikut.

I. Bait Pertama

Bunga balluru nu teteng (bug blur nuetet) $u$

Tajuktonjong nu soeang (tjutojonusoeaa)

Bunga rambega (bug rebg)

Ma(d) dongko risimbolenna (mdoko risiboelnu).

Artinya:

Bunga mekar kau pegang Bunga

tanjung kau ayunkan Bunga

rambega

Tertancap disanggulmu.

Kutipan bait kelong di atas menyatakan pujian bagi para penari Salonreng yang sedang menarikan tarian tersebut. Ada pun perlambangan bunga pada bait di atas menandakan keindahan bunga yang diibaratkan dimiliki oleh para penari Salonreng.

II. Bait kedua

Maklonre-lonre pi raya (mloer-loer piry)

Nanukanarisoknaya (nnuknrisokny)

Sungguh ko antu (sugu ko at)u

Katutui mateknea. (ktutuaimetena).

Artinya:

Berbondong-bondong ke Utara

Berkata pada mimpi Sungguhlah

Menjaga keharmonisan

Bait kedua ini mengungkapkan pesan bahwa bagi mereka yang Halaman $\mid 602$ 
mensyukuri nikmat Tuhan akan bahagia di hari kemudian. Nikmat yang dimaksud adalah nikmat baik berupa hasil alam, mata pencaharian, dan nikmat kebahagiaan dunia. Bait ini pula memaparkan tentang sebuah mimpi dan kesungguhan masyarakat menjaga keharmonisan baik antara keluarga, keharmonisan antarkelompo kmasyarakat, maupun keharmonisan manusia dengan alam sekitarnya.

III. Bait ketiga

Nampannanaung ributta (npnnauri but)

Na napasanga AnrongKu (n npsgaroku)

Empoko Tuna (eapoku tun)

Si Dongkokamse-kamase. (sidokokmes-mes).

Artinya:

Baru turun ke tanah

Lalu orang tuaku berpesan

Bersusah-susahlah Bersama

dalam kemiskinan

Pada bait ketiga ini mengungkapkan pesan orang tua atau leluhur kepada anak generasi mereka agar bersifat hati-hati dan mawasdiri dalam hidup, walau hidup miskin dan dalam kesusahan harus tetap menjaga kebersamaan di antara masyarakat dan anggota keluarga khususnya.

IV. Baitkeempat

Pauangi anak ri book (pauagi an riboko)

Pasangi anak tanjari (psgi an tjri)

Jagai Lalo (jgaillo)

Adat patturiOloannu (ad pturiaolonu).

Artinya:

Pada bait ini mengungkapkan pesan orang tua khususnya seorang ibu terhadap anaknya, "Setiap engkau bepergian, jagalah norma susilamu". Maksudnya, kemanapun kakimu berpijak bawalah norma susila yang baik atau pegang teguhlah adat istiadat yang leluhurmu tanamkan sejak dulu.

v. Bait kelima Apainrannurianja (ap airnuriaj)

Tukaranuriakhera

(tukrnuriaehr)

Nanubokoi anak banribulaennu. (nnubokoai an bribuleanu).

Artinya:

Apa saja hutangmu

Yang akan ditukarkan di akhirat

Sehingga kau tinggalkan anak kesayanganmu.

Bait mengungkapkan pesan berupa ancaman atau pengingat sebelum ajal kematian tiba, "apa gerangan hutang dan sangkutanmu di akhirat, sampai hati meninggalkan anak kesayanganmu".

Keseluruhan teks Kelong Salonreng ini memiliki pola persajakan 8-8-4-8, Halaman | 603 
Volume 6 Nomor 2

seperti pola sajak Royong Makassar. Artinya setiap baris dari kelong ini ada yang jumlah suku katanya 8 dan ada juga yang jumlah suku katanya 4 .

2. Pendeskripsian Makna Kelong Salonreng dihubungkan dengan Kehidupan Sosial Budaya Masyarakat Desa Ara

a. Lokasi dan Keadaan Alam

Desa Ara merupakan salah satu desa di Kabupaten Bulukumba yang terletak kira-kira 187 km dari kotamadya Ujung Pandang (Makassar) jazirah selatan Sulawesi Selatan. Di sebelah utara Desa Darubiah (pemekaran dari Desa Bira).

Desa Ara berbatas:

1) Sebelah Utara berbatasanbdenganbLembanna

2) Sebelah Timur berbatasanbdenganbTeluk Bone

3) Sebelah Selatan berbatasanbdenganbDarubiah

4) Sebelah Barat berbatasanbdenganbKelurahan

Tanah Lemo Luas Daerah

Desa Ara terdiri dari dua Dusun, yaitu:

1) Dusun Bontona $=6 \mathrm{Km} 2$

2) Dusun Maroanging Tinadung $=9 \mathrm{Km} 2$ 
Jadi, luas daerah Desa Ara adalah $15 \mathrm{Km} 2$ yang terdiri atas bukit kapur dan padang rumput serta hutan-hutan. Pada bagian Timur, terdapat lembah yang subur yang merupakan daerah pertanian yang menghasilkan palawija berupa jagung, kacang-kacangan, dan lain-lain.

b. Penduduk dan Mata Pencaharian/Demografi

Penduduk Desa Ara yang mendiami dusun yang jumlah penduduknya sebanyak 2.370 jiwa, yang terdiri dari laki-laki 1091 jiwa dan perempuan sebanyak 1.279 jiwa yang terhimpun dalam kepala keluarga. Ekonominya disamping masih bertumpu pada pertanian, maka pencaharian utamanya adalah bertukang, termasuk seluruh jenis pertukangan perahu, sehingga orang Ara menguasai tempat-tempat centra industry pembuatan kapal layar/motor di beberapa tempat di Nusantara.

Di samping itu, tenaga kerja wanita di Desa Ara ini meruapakan tenaga kerja yang produktif. Hal ini terlihat dalam usaha kerajinan seperti menjahit dan beberapa jenis sulaman yang pemasarannya sampai ke luar provinsi.

c. Agama dan Kepercayaan

Adapun agama yang dianut oleh penduduk Ara adalah agama islam. Diperkirakan agama islam mulai berkembang pada abad ke-17. Pada masa perkembangan agama islam di bagian Timur Bulukumba oleh Datok di Tiro. d. Latar Belakang Sejarah Keberadaan Tari Salonreng

Sejak dahulu kala tata kehidupan masyarakat Ara dilatarbelakangi dengan seni yakni adat istiadat, bahasa, mata pencaharian dan berbagai jenis keterampilan yang menonjol yang memperkuat pertahanan Armada Kerajaan Bone pada zamannya, dan diberi nama "Ellung Mangenre" yang dikerjakan oleh Daeng Mangali dan kawan-kawan.

Demikian pula dengan memenuhi pesanan seorang tamu asing dari Inggris (Fa. Gollins) sebuah perahu yang dibuat di pantai Ara sebelum Perang Dunia II.

Seni mereka ditampakan pula pada pembuatan perahu perak termasuk layar dan tali temalinya yang dilengkapi dengan sebuah Gong kecil yang berbentuk Gong Salonreng, yang juga bahannya terbuat dari perak. Panjang perahu 1 meter, yang dikerjakan oleh seorang pandai perak yang bernama Baso Tende', atas instruksi Gubernur Jenderal Belanda di Batavia pada masa itu melalui kontroler Bulukumba (P. Smith). Setelah selesai, kemudian dikirim ke Nederland.

Ditampakkan pula pada gaya bahasanya yaitu Royong (pantun), bahasa khas Ara yang sering dipakai (diucapkan), keindahan bahasa yang masih 
mutlak digunakan sampai sekarang utamanya dalam acara meminang.

Di samping seni kerajian dan seni berpakaian tersebut di atas, terdapat pula sebuah seni yang sangat akrab dengan kehidupan masyarakat Ara secara turun temurun yakni tari Salonreng. Menurut informasi dari pemilik kebudayaan Bonto bahari kabupaten Bulukumba (narasumber) bahwa pada mulanya tarian ini berkembang di Desa Ara sejak abad ke-18. Dalam masa pemerintahan Karaeng Bontobiraeng yang memerintah, di Desa Ara pada masa itu.

Tari Salonreng merupakan perkembangan dari sebuah tari rakyat yang mempunyai gerakan yang sangat sederhana yang dimainkan secara tunggal atau kelompok penari wanita, yang berfungsi sebagai penghormatan kepada leluhur atau nenek moyang, atau digunakan untuk menghalau roh-roh jahat serta memohon perlindungan dari Dewata, agar negeri terhindar dari berbagai penyakit menular (ganringpua). Kemudian tari ini berkembang dengan mengalami perubahan, dengan gerakan yang indah yang dinamakan Tari Salonreng yang artinya: Salonreng diambil dari kata Lonre (maklonre-lonre) yang artinya berbondong-bondong. Maksud dari kata berbondong itu karena pada zaman dahulu diadakan semalam suntuk, maka kelompok penari bergantian menarikannya dibarung-barung (anjungan). Karena ekonomi masyarakat Ara pada masa itu tidak stabil akibat pendudukan Jepang pada tahun 1942-1945, yang mengakibatkan banyak masyarakat Ara kekurangan bahan makanan, pakaian, dan lain-lain. Sehingga pada masa itu banyak masyarakat Ara yang menjual peralatan tarinya.

e. Seniman dan Masyarakat Pendukung

Sejak abad ke-18 sampai dengan pecahnya Perang Dunia ke II merupakan kewajiban bagi gadis-gadis di Desa Ara mempelajari tari Salonreng karena seorang anak perempuan bila sudah disebut gadis merupakan aib baginya apabila gadis tersebut tidak dapat menarikan Salonreng tersebut. Sehingga setiap orang yang mempunyai anak gadis selalu membekali anaknya sejak kecil dengan latihan-latihan dasar tari yang disebut dengan Annepo' (pacul). Namun sering diajarkan secara tidak langsung dan dijadikan sanksi atas ganjaran pelanggaran saat sang anak melakukan kesalahan atau etika sopan santun. Dengan demikian tari salonreng ini telah menyatu dengan diri masyarakat Ara secara turun temurun. 
Jurnal Onoma: Pendidikan, Bahasa dan Sastra PBSI FKIP Universitas Cokroaminoto Palopo

Volume 6 Nomor 2
ISSN 2443-3667 (print)

ISSN 2715-4564 (online)

\section{Simpulan}

Kesimpulan dari penelitian ini adalah sebagai berikut:

1. Makna kelong Salonreng setiap baitnya dihubungkan dengan semiotika Marcel Danesi yang terdiri atas tiga poin penting yaitu pesan, tanda dan makna. Kelong Salonreng adalah kelong yang dinyanyikan dalam upacara "akkarena siusiri" perkawnan. Kelong Salonreng terdiri atas pujian, sindiran dan nasihat-nasihat. Setiap bait kelong pada upacara adat perkawinan hanya terdiri atas empat baris dan setiap barusnya terikat dengan jumlah suku kata dan bersajak seperti pola sajak Makassar. Jumlah suku katanya masing-masing adalah: Baris pertama, kedua dan keempat terdiri atas 8 suku kata, sedangkan baris ketiga hanya terdiri atas 4 suku kata pada setiap bait kelong tersebut (pola persajakan Makassar 8-8-4-8).

2. Bentuk interelasi makna kelong Salonreng dengan kehidupan social budaya masyarakat Desa Ara Kabupaten Bulukumbadilihat dari beberapa aspek kehidupan dalam masyarakat, misalnya: Sejarah tari Salonreng dilihat dari aspek lokasi, keadaan alam, keadaan penduduk (masyarakat Desa Ara), mata pencaharian, agama(kepercayaan) seniman serta masyarakat pendukungnya. 


\section{Daftar Pustaka}

Alwi, Hasan. 2003. Tata Bahasa Baku Indonesia. Edisi Ketiga. Jakarta: Balai Pustaka. Anwar, Ahyar. 2008. Semiotika Sastra. FBS Makassar: Universitas Negeri Makassar. Bratawidjaja, Thomas. 1990. Upacara Adat Perkawinan Sunda. Jakarta: Pustaka Sinar Harapan.

Chaer, Abdul. 2002. Psikolinguistik. Jakarta: PT Rineka Cipta.

Chaer, Abdul. 2003. Linguistik Umum. Jakarta: PT Rineka Cipta.

Depdikbud. 2008. Kamus Besar Bahasa Indonesia Edisi Keempat. Jakarta: PT Gramedia Pustaka Utama.

Endraswara, Suwardi. 2003. Metodologi Penelitian Sastra. Yogyakarta: Pustaka Widyatama.

Gani, Andi. 1989/1990. Elong Ugi (Kajian Naskah Bugis). Makassar: Departemen Pendidikan dan Kebudayaan Bagian Proyek Penelitian dan Pengkajian Kebudayaan Sulawesi Selatan.

Juanda. 2010. Penelitian Kebudayaan. Jakarta.

Juanda. 2010. Sejarah Kebudayaan Indonesia. Jakarta.

Mardiana. 2004. Tinjauan Makna Semantik Teks Kelong Salonreng pada Perkawinan Masyarakat Ara Bulukumba. Skripsi Makasar: UNHAS.

Maran, Rafael Raga. 1999. Manusia dan Kebudayaan dalam Perspektif Ilmu Budaya dasar. Jakarta: Rineka Cipta.

Pateda, Mansoer. 1996. Semantik Leksikal. Gorontalo: Rineka Cipta.

Pradopo, Rachmat Djoko. 1993. Pengkajian Puisi (Analisis Strata Norma dan Analisis Struktural dan Semiotik). Yogjakarta. Pustaka Pelajar.

Ratna, Nyoman Khuta. 2004. Teori, Metode dan Teknik Penelitian Sastra. Denpasar: Pustaka Pelajar.

Ratna, Nyoman Khuta. 2006. Estetika Sastra dan Budaya. Denpasar: Pustaka Pelajar.

Riffaterre, Michael. 1978. Semiotic Of Poetry. USA: Library of Congres Cataloging in Publication Data.

Sugiyono. 2009. Memahami Penelitian Kualitatif. Bandung: Alfabeta.

Teeuw, A. 1982. Sastra dan Ilmu Sastra. Jakarta: Pustaka Jaya.

Wahid, Sugira. 2007. Manusia Makassar. Makassar: Pustaka Refleksi Lokal. 